\title{
Las emociones en las representaciones sociales del cambio climático ${ }^{1}$
}

\section{Emoções nas representações sociais das mudanças climáticas}

\section{Emotions in social representations of climate change}

\author{
Raul Calixto Flores* \\ Esperanza Terrón Amigón ${ }^{* *}$
}

\begin{abstract}
RESUMEN
El artículo describe una investigación en educación ambiental, entre sus objetivos, se propone describir los principales componentes de las representaciones sociales del cambio climático en una muestra de estudiantes de la Universidad Pedagógica Nacional, México; el trabajo consistió en una investigación cualitativa, recuperando el discurso de los estudiantes; en los resultados es posible identificar la presencia de las emociones en las representaciones sociales del cambio climático. Éstas no se reducen a reacciones o respuestas instintivas, son componentes complejos, comprenden aspectos psicológicos y sociales, que se observan en expresiones valorativas. Entre las conclusiones obtenidas se destaca que las emociones constituyen un componente relevante en las representaciones sociales y pueden ser investigadas desde el campo de la educación ambiental.

Palabras clave: Educación ambiental. Emociones. Representaciones sociales. Cambio climático.
\end{abstract}

1 El presente artículo es producto de una investigación aprobada en el Área académica: Diversidad e Interculturalidad de la Universidad Pedagógica Nacional, México.

*Universidad Pedagógica Nacional, México. E-mail: calixto07@gmail.com. https://orcid. org/0000-0001-7940-3299

** Universidad Pedagógica Nacional, México. E-mail: espete_82@yahoo.com.mx. https:// orcid.org/0000-0001-9707-1953 


\title{
RESUMO
}

O artigo descreve uma pesquisa em educação ambiental que, entre seus objetivos, propôs-se a descrever os principais componentes das representações sociais das mudanças climáticas em uma amostra de alunos da Universidade Pedagógica Nacional do México. Essa pesquisa consistiu em uma investigação qualitativa, recuperando o discurso dos alunos, que por meio dos resultados foi possível identificar a presença das emoções nas representações sociais das mudanças climáticas. Essas não são reduzidas a reações ou respostas instintivas, são componentes complexos que incluem aspectos psicológicos e sociais, que são observados em expressões de valor. Entre as conclusões obtidas, enfatiza-se que as emoções constituem um componente relevante nas representações sociais e podem ser investigadas no campo da educação ambiental.

Palavras-chave: Educação ambiental. Emoções. Representações sociais. Mudanças climáticas.

\begin{abstract}
This article describes a research in environmental education that has, among its objectives, the intention of describing the main components of the social representations of climate change in a sample of students of the National Pedagogical University of Mexico. The research consisted of a qualitative investigation, recovering the discourse of the students; in the results it is possible to identify the presence of emotions in the social representations of climate change. These are not reduced to instinctive reactions or responses; they are complex components, they include psychological and social aspects, which are observed in expressions of value. Among the conclusions obtained, there is an emphasis on the fact that emotions constitute a relevant component in social representations and can be investigated from the field of environmental education.
\end{abstract}

Keywords: Environmental education. Emotions. Social representations. Climate change.

\section{Introducción}

La educación ambiental en las instituciones de educación superior es fundamental para lograr una formación integral de los jóvenes, con la cual contribuyan a hacer realidad los objetivos del desarrollo sostenible, y la prevención 
de la generación de los gases de efecto invernadero, así como para atender los efectos del cambio climático. Fenómeno que hace referencia a las fluctuaciones a largo plazo de la temperatura, las precipitaciones, los vientos y el resto de los componentes del clima en la Tierra (IPCC, 2013).

Entre los objetivos de la educación ambiental plasmados en la conferencia internacional de Tbilisi, se encuentra:

(...) lograr que los individuos y las colectividades comprendan la naturaleza compleja del medio ambiente natural y del creado por el hombre, resultante de la interacción de sus aspectos biológicos, físicos, sociales, económicos y culturales y adquieran los conocimientos, los valores, los comportamientos y las habilidades prácticas para participar responsable y eficazmente en la prevención y solución de los problemas ambientales y en la gestión de la cuestión de la calidad del medio ambiente (UNESCO, 1978, p. 28).

Este tipo de educación puede contribuir a la construcción de diversas vías, para lograr estilos de vida que apoyen la integridad ecológica, la justicia social y económica, los modos de vida sostenibles y el respeto a toda forma de vida; aprender a prevenir y resolver conflictos, respetar la diversidad cultural, crear una sociedad con un profundo respeto al cuidado y una vida en paz; aprender de los pueblos indígenas y los patrones tradicionales de vida que respetan y honran la Tierra y sus sistemas de apoyo a la vida; adaptar esta sabiduría al mundo contemporáneo que cambia rápidamente; hacer escogencias individuales, comunitarias, nacionales y hasta globales con la debida consideración hacia el bien colectivo (UNESCO, 2007).

En diversos documentos internacionales, como los objetivos para el Desarrollo Sostenible y las resoluciones de Río +20 , se reconoce la importancia de promover la educación ambiental en la juventud, para formar una conciencia ambiental sobre la importancia de prevenir o mitigar los efectos de los diversos problemas ambientales, como el cambio climático (NACIONES UNIDAS, 2012). En congruencia con éste y otros pronunciamientos, se han desarrollado en México y en la mayoría de los países del mundo diversos programas de educación ambiental en las instituciones de educación superior.

En este artículo solo se destacan algunos de los principales resultados de la investigación realizada en una institución de educación superior de México: Universidad Pedagógica Nacional; investigación que tuvo entre sus objetivos, describir los principales componentes de las representaciones sociales del cambio climático. 
La teoría de las representaciones sociales desarrollada en un inicio por Serge Moscovici (1979) en la década de los sesenta del siglo anterior, es utilizada en numerosos proyectos de investigación educativa; es así como en el campo de la educación ambiental ha sido recuperada en diversos estudios, entre los que se encuentran los referidos al cambio climático.

Las representaciones sociales del cambio climático de los estudiantes universitarios incluyen contenidos representacionales, concepciones alternativas, actitudes y emociones que forman parte de las dimensiones de información, campo de representación y actitudes. Entre los componentes poco estudiados de la representación social se encuentran las emociones, por lo que uno de los objetivos del estudio que se describe en el presente artículo es el de identificar el componente emocional de las representaciones sociales del cambio climático.

\section{Las representaciones sociales}

El empleo de la teoría de las representaciones sociales es relevante para la educación ambiental, ya que contribuyen a caracterizar la posición de las personas respecto a diversos aspectos de la vida cotidiana. Las representaciones sociales se refieren al llamado "conocimiento de sentido común", con el cual las personas en la vida cotidiana toman diversas decisiones para interactuar con otras personas y enfrentar las diversas situaciones que se les presentan.

Las representaciones sociales son entidades casi tangibles. Circulan, se cruzan y se cristalizan sin cesar en nuestro universo cotidiano a través de una palabra, un gesto, un encuentro. La mayor parte de las relaciones sociales estrechas, de los objetos producidos o consumidos, de las comunicaciones intercambiadas están impregnadas de ella (MOSCOVICI, 1979, p. 27).

Moscovici plantea que las representaciones sociales comprenden tres dimensiones: la información, el campo de representación y la actitudinal, que al integrarse constituyen a la representación social.

En la dimensión de información se organizan los conocimientos, el campo de representación abarca los contenidos limitados y concretos, y la dimensión de actitudes, se refiere a la orientación global hacia el objeto de representación. 
La teoría de las representaciones sociales centra su atención en el conocimiento de sentido común, referido a grandes parcelas de la realidad, como el mundo físico, el mundo de la vida o el mundo social, o aspectos muy limitados como una práctica profesional específica.

Desde la psicología social, las representaciones adquieren el atributo de sociales:

Las representaciones son construcciones sociales; consensan imágenes $\mathrm{y}$ anhelos de las personas de un grupo, de una comunidad o sociedad. Lo social tiene un doble significado: a) como elaboración compartida junto con las personas cercanas y los contemporáneos, b) como significado de una acción, un acontecimiento o un bien cultural (PIÑA, 2004, p. 32).

Las representaciones sociales consideran la génesis del conocimiento social dentro de un marco cultural y de interacción, en el que los medios de comunicación contribuyen a su conformación.

Las representaciones sociales son una red de interactuar conceptos e imágenes cuyo contenido evolucionar continuamente con el tiempo y el espacio. Cómo la red evoluciona depende de la complejidad y la velocidad de comunicación, así como en los medios de comunicación disponibles. Y sus características sociales están determinadas por las interacciones entre los individuos y / o grupos, y el efecto que tienen sobre sí como una función de la relación que les une (MOSCOVICI, 1988, p. 220).

Las representaciones sociales son una forma de conocimiento de sentido común y práctico, que permite obtener una mirada funcional del mundo; se orientan hacia la comunicación, la comprensión y dominio del entorno material y social.

El objeto de representación puede ser diverso, ya que comprende un conocimiento socialmente compartido, que ha sido elaborado en la esfera de la producción del conocimiento científico y transmitido por los medios de comunicación, de modo que emerge de las representaciones sociales la necesidad de convertir lo extraño en familiar (MOSCOVICI, 1979).

Los sujetos de representación son múltiples y corresponden a los grupos que se apropian del objeto de representación, el cual está presente en las conversaciones cotidianas; Moscovici señala que de acuerdo con el grado de 
congruencia entre las dimensiones es posible identificar criterios para delimitar a los sujetos de representación; advierte que los estudiantes a pesar de su diversidad llegan a constituir un grupo relativamente bien definido.

En la investigación que dio origen al presente artículo el objeto de representación es el cambio climático, los sujetos de representación son los estudiantes de la Universidad Pedagógica Nacional.

El cambio climático es reconocido por la mayoría de los integrantes de la comunidad científica como un problema que repercute en las condiciones climatológicas del planeta:

\begin{abstract}
Variación del estado del clima, identificable (por ejemplo, mediante pruebas estadísticas) en las variaciones del valor medio o en la variabilidad de sus propiedades, que persiste durante largos períodos de tiempo, generalmente decenios o períodos más largos. El cambio climático puede deberse a procesos internos naturales o a forzamientos externos tales como modulaciones de los ciclos solares, erupciones volcánicas o cambios antropógenos persistentes de la composición de la atmósfera o del uso del suelo. (IPCC, 2014, p. 5).
\end{abstract}

En la actualidad del cambio climático se habla en la televisión, radio e internet, se lee en múltiples implicaciones y es estudiado en las universidades.

El cambio climático se percibe socialmente como un problema de carácter global, deslocalizado en el tiempo y en el espacio y demasiado abstracto (MEIRA, 2009).

La investigación en educación ambiental también ha estudiado este fenómeno desde su dimensión social. Entre otras investigaciones que han abordado las representaciones sociales del cambio climático, se encuentran: Meira (2012); Meira y Arto (2013); Jaspal, Nerlich y Cinnirella (2014); Bello, Meira y González-Gaudiano (2017); Terrón (2017) y Calixto (2017), entre otras.

Estas investigaciones aportan información para la educación ambiental, ya que las representaciones se pueden relacionar con la práctica de este campo, siendo una base para propiciar procesos de aprendizaje significativos en los estudiantes.

\title{
Proceder metodológico
}

Para lograr los objetivos se desarrolló una investigación cualitativa, recuperando el discurso de los estudiantes, se trabajó con una encuesta y una 
entrevista. La primera como técnica cualitativa requiere de la construcción de un cuestionario que privilegie la expresión abierta de los sujetos. La encuesta comprendió varios cuestionarios (censal, asociación de palabras, escala Lickert) que permitieron en primera instancia identificar las características de la población de estudio, la presencia de la representación social del cambio climático, los componentes de las representaciones, entre los que se encuentran las emociones.

Por otra parte, la entrevista cualitativa (evocada a partir de imágenes), es considerada como una de las técnicas más pertinentes para el estudio de las representaciones sociales. En esta técnica, se utilizó un conjunto de imágenes referidas al cambio climático, lo que permitió, entre otros aspectos, generar una mejor comunicación con los estudiantes.

Se les presentaron las imágenes a los estudiantes, para que seleccionaran aquellas que les representó un significado, después las organizaron de acuerdo con el impacto que les originó, y en seguida platicaron sobre la imagen y dieron respuesta a las preguntas. La información obtenida, se analizó buscando regularidades en las expresiones, por medio del análisis de contenido (BARDÍN, 1986; KRIPPENDORFF, 1990); se organizó el material en unidades comparables de categorización para análisis temático.

La muestra del estudio fue aleatoria, selectiva, se dirigió a 105 estudiantes del $6^{\circ}$ y $8^{\circ}$ semestres de las cinco licenciaturas escolarizadas de la unidad Ajusco: administración educativa, educación indígena, pedagogía, psicología educativa y sociología de la educación. Se seleccionaron para el estudio 21 estudiantes de cada licenciatura.

\section{Resultados}

En la investigación con los estudiantes de la Universidad Pedagógica Nacional, fue posible identificar la existencia de representaciones sociales del cambio climático, identificando una mayor proporción de contenidos sobre efectos del cambio climático, que de sus causas, al igual que los resultados obtenidos por González-Gaudiano y Maldonado (2012) y Terrón (2017); pero también se detectaron diversas concepciones alternativas, en aspectos referidos a las causas del cambio climático, resultados que coinciden con los hallazgos de Reusswig y Meyer (2014).

En los resultados es posible identificar la presencia de las emociones en la representación social del cambio climático; éstas no se reducen a reacciones o respuestas instintivas, son componentes complejos, comprenden aspectos psico- 
lógicos y sociales, que se observan en expresiones valorativas. En la socialización primaria el componente afectivo está presente y ocurre una adhesión emocional con los objetos que adquieren una significancia (BERGER; LUCKMANN, 2005); esta carga emocional no desaparece, en la socialización secundaria se mantiene y se manifiesta ante objetos con los cuales se identifican las personas.

Para Gutiérrez (2013, p. 28), “...las emociones son inseparables de toda producción subjetiva humana, en este sentido son constituyentes de las propias representaciones sociales".

En la investigación realizada con los estudiantes de la Universidad Pedagógica Nacional las emociones se identificaron a partir del análisis del contenido de las expresiones que emergieron de las entrevistas.

La Universidad Pedagógica Nacional, se encuentra organizada en diversas "unidades académicas", la investigación se realizó en la unidad Ajusco de la ciudad de México, donde se ofrecen cinco licenciaturas escolarizadas: administración educativa, educación indígena, pedagogía y psicología educativa. Estudiantes de estas cinco licenciaturas formaron parte del estudio.

En el análisis de resultados, la licenciatura de procedencia de los estudiantes se indica por medio de letras y al estudiante con un número: Administración educativa: Ae; Educación Indígena: Ei; Pedagogía: Pe; Psicología educativa: Ps; Sociología de la educación: Se.

En las respuestas de las entrevistas a los estudiantes, se hace explícito el componente emocional de las representaciones sociales; entre las emociones expresadas se encuentran la indignación, tristeza, miedo, desconfianza, impotencia, enojo y pesimismo, entre otras. Las emociones no se restringen al plano psicológico, éstas se encuentran en un plano psicosocial.

Los estudiantes expresan distintas emociones por los efectos de los múltiples problemas ambientales, y en específico en los comportamientos de los seres humanos hacia la naturaleza; señalan una ruptura del ser humano con el medio ambiente; reconocen que la gran mayoría de las personas tienen inconciencia en el manejo de los bienes naturales y eso les origina una insatisfacción.

\section{Indignación}

Los estudiantes manifiestan enfado por el estado en que se encuentra el medio ambiente, identifican una falta de sintonía entre la realidad cotidiana y el discurso oficial. 
... es indignante la tala de árboles, en cada momento de la historia hemos utilizado los recursos para nuestro beneficio y con el talado de árboles, se provoca la desertificación, los árboles, entre otras cuestiones, ayudan a evitar las inundaciones (Pe/13).

... el hombre se ha vuelto un ser depredador, ya que de todo se apropia, y es que cada generación va siendo más insensible con el cuidado del medio ambiente, la mercadotecnia, la industria busca poseer la naturaleza, para después destruirla, esto me indigna, no estoy de acuerdo (Ps/10).

También los estudiantes muestran indignación, por falta de comprensión de los seres humanos de los efectos negativos de las actividades productivas intensivas, que no toman en cuenta los ciclos naturales del planeta. La indignación, se extiende a los propios universitarios, que desarrollan comportamientos no favorables con el medio ambiente.

De acuerdo con los estudiantes, los intereses de la sociedad moderna se encuentran en la acumulación de los bienes naturales, más que sobre el cuidado del medio ambiente; observan la falta de sensibilidad hacia el cuidado del medio ambiente.

\section{Tristeza}

La tristeza es una de las emociones básicas de todo ser humano, que se expresa en un estado anímico negativo, por cuestiones que parecen irreversibles y que no se atienden.

... porque es un problema que afecta a mi localidad, me siento triste, porque es a lo que estamos llegando (Se/10).

... me da tristeza, ¿qué dejamos a las nuevas generaciones?, gastan a lo menos el agua y muchos sufren... (Pe/15). 
En múltiples expresiones de los estudiantes, se observa la tristeza en las situaciones ambientales que se presentan en su entorno inmediato; las emociones se entrecruzan, no se encuentran asiladas, una emoción conduce a otra. Los estudiantes reflexionan sobre las implicaciones del cambio climático para las futuras generaciones, en las expresiones gestuales y verbales se refleja una impotencia para cambiar las situaciones que alteran las condiciones del medio ambiente.

\section{Miedo}

El miedo es una emoción que valora la situación del medio ambiente como negativa, y que puede originar algún daño personal o a los integrantes de su comunidad.

... siento miedo, angustia, desesperación y nervios de pensar que estamos destruyendo nuestro planeta, que México y todo el mundo está en decadencia porque todos somos seres vivos y hay que respetar la diversidad y la biodiversidad (Se/15).

...me remito a mi comunidad, la tala inmoderada, se acaban las plantas, el agua en su comunidad se quedan sin agua y comida, y tienes miedo porque no hay que comer, queda sólo emigrar para ganar dinero en otra parte, más que nada (Ei/9).

Otra de las emociones que prevalecen en las expresiones de los estudiantes es el miedo personal, pero también por el destino de su familia, amigos y compañeros. El miedo se relaciona con los efectos personales y comunitarios del cambio, sobre todo por la escasez que se puede presentar de los bienes para obtener un sustento.

\section{Desconfianza}

Los estudiantes no tienen seguridad sobre la existencia de condiciones favorables del medio ambiente en el futuro, ya que las acciones presentes no se dirigen para darle solución a los problemas ambientales. 
“...que está pasando en nuestro planeta sólo es consecuencia de lo que hemos provocado por nuestra inconciencia, ¿qué pasará en el futuro?... lo mismo" (Ps/20).

“...si las personas tuvieran confianza de que la problemática ambiental se está resolviendo, cambiarían sus comportamientos, todos en conjunto podríamos realizar un cambio, tal vez la solución no sea solo reforestar al planeta, pero pienso que sería una acción muy importante, pues implantarle vida a nuestro planeta y cuidarlo, pero en la actualidad no podemos confiar que se están haciendo bien las cosas" (Pe/2).

También, algunas expresiones de los estudiantes atribuyen la crisis planetaria a la inconciencia de los tomadores de decisiones, generando desconfianza sobre lo que se puede hacer en torno al cambio climático. Los estudiantes consideran que la confianza, puede ser la base para realizar un cambio, y mejorar las condiciones del planeta; pero sobre todo subrayan que en la actualidad las acciones de los tomadores de decisiones no han tomado en cuenta la prevención, sino solo sus intereses personales.

\section{Impotencia}

Los estudiantes, ante la imposibilidad del cambio, sienten que poco o nada pueden hacer para revertir las condiciones negativas del medio ambiente, ya que paradójicamente observan que se "cambia" para que prevalezca igual el estado de las cosas.

... me siento incómoda por no poder hacer nada ante lo que está pasando, ocurre un desequilibrio ambiental, en algunos lugares hay exceso de calor $y$ produce sequías, $y$ en otros lugares, las intensas lluvias que provocan inundaciones, lo peor es que los únicos afectados son las personas que habitan estos lugares... (Se/13).

Qué hacer...si denuncias o haces algo, no pasa nada... vivimos en un país que se depredan los recursos y se contamina, y no pasa nada (Ae/21). 
La impotencia produce incomodidad para algunos de los estudiantes. Esta es una de las emociones más frecuentes entre los entrevistados, porque observan a su alrededor que, en lugar de mejorar las condiciones ambientales, éstas se van deteriorando, y que las acciones personales poco ayudan; los estudiantes carecen de los medios para ejercer un control ante las situaciones que dan origen al cambio climático.

\section{Enojo}

Otra emoción recurrente en los estudiantes es el enojo, como puede observarse en las siguientes expresiones.

... me enojo, es porque no puedo hacer algo, existen muchas campañas, sin embargo, crece el cambio climático, no hay muchas cosas. Vemos nuestro mundo destruido, como una consecuencia de nuestros descuidos $(\mathrm{Pe} / 12)$.

... enojo, porque hav personas inconscientes que ven solo sus intereses $y$ creen que con dinero solucionan todo, mientras otros no tienen que vestirse o que comer $(\mathrm{Se} / 4)$.

El enojo es una emoción que manifiesta un alto estado de frustración, ante una situación injusta, como es el estado deplorable del medio ambiente. Ante la imposibilidad de resolver los problemas ambientales, algunos estudiantes indican que se sientes enojados, porque unos cuantos se benefician, en perjuicio de miles y millones de seres humanos.

\section{Pesimismo}

El pesimismo es un estado emocional que se caracteriza por la imposibilidad de identificar un rasgo favorable en la situación en que se encuentra en el medio ambiente. 
... cada vez nos quedamos más pobres, sin economía, sin la naturaleza, como un reflejo de lo que estamos perdiendo...todo se acaba, el agua se acaba, los animales se extinguen ... no tenemos futuro (Ps/17).

... expresa que los humanos de hoy en día somos muy egoistas, ya que a través de satisfacer nuestras necesidades estamos afectando al mundo sin importarnos las nuevas generaciones, que no tienen la culpa de las acciones realizadas en el presente... ( $\mathrm{Pe} / 1)$.

El pesimismo se manifiesta en los estudiantes ante la imposibilidad de resolver las causas y efectos del cambio climático. Es común entre los estudiantes el pesimismo respecto a la extinción de animales y agotamiento del agua, como efectos del cambio climático. El pesimismo se deriva del reconocimiento del egoísmo de las personas y ante la sensación de poder cambiar la situación: existe un pesimismo por el presente y por el futuro.

En las emociones se identifican en los estudiantes una falta de credibilidad de las acciones que se están realizando a favor del medio ambiente; las condiciones que observan del entorno inmediato no corresponden al discurso institucional.

\section{Discusión y conclusiones}

Los resultados obtenidos son similares a otros estudios referidos a la investigación en educación ambiental que han utilizado como marco de referencia las dimensiones de las actitudes, entre otras, se encuentran, Grob (1995); Durán, Alzate, López y Sabucedo (2007); y Kollmus y Agyeman (2002).

La suma de las emociones anteriormente referidas puede llevar a los estudiantes a una afectación personal, que manifiestan de diversas formas, pero que se caracteriza por la imposibilidad personal de actuar. Se identificaron en todas las dimensiones de las representaciones componentes emocionales sobre el cambio climático; en forma coincidente a lo señalado por Meira y Arto (2013).

El cambio climático, en efecto como objeto de representación "es una entidad material, imaginaria o simbólica que la gente nombra, y a la cual se le atribuyen características y valores, lo que permite hablar acerca de ésta" (WAGNER; HAYES; FLORES, 2010, p. 220); como se observa predominan las emociones negativas ante los efectos del cambio climático. 
Entre los componentes que dan sentido a las representaciones están las emociones, pero cuando en éstas predomina una tendencia negativa, se hace necesario revisar las acciones de las políticas públicas y ambientales, que han tenido tan magros resultados en los últimos años. Durkheim (1998) planteó que la constitución de los grupos ocurre básicamente porque se busca a quienes piensan y sienten como nosotros; en este sentido los estudiantes de la Universidad Pedagógica a pesar de que pertenecen a diferentes licenciaturas comparten las mismas emociones que se encuentran en la matriz de las representaciones.

Las emociones identificadas en los estudiantes, como un componente significativo de las representaciones sociales, plantean una vía alternativa para la actuación de la educación ambiental ante el cambio climático; y de su relación como guía para la práctica. Las emociones constituyen un componente relevante en la representación social y es importante investigarlas desde el campo de la educación ambiental, considerando sus implicaciones educativas.

Las emociones tienen una relación intrínseca con las representaciones sociales, se requiere comprenderlas como: “...portadoras de interpretaciones y significados dependientes de consideraciones sociales y culturales que definen los momentos y las circunstancias en que debe ser experimentada cada una de ellas y con qué grado de intensidad debe hacerse" (GUTIÉRREZ; ARBESÚ; PIÑA, 2012, p. 31).

En este marco se hace necesario considerar el componente emocional como fundamental para comprender el sentido que se le confiere al cambio climático.

Los resultados obtenidos en el presente estudio identifican la existencia de representaciones sociales del cambio climático en los estudiantes universitarios; y a las emociones como uno de sus componentes más importantes, en éstas se observa una tendencia pesimista en los estudiantes de la Universidad Pedagógica Nacional; es notoria la preocupación por realizar acciones, pero también se identifican en su gran mayoría acciones de adaptación, y escasas acciones de resiliencia. El conjunto de emociones manifiestas tiene un alto componente negativo, de desesperanza, y conducen a los estudiantes a la apatía por actuar. Es necesario buscar estrategias en la educación ambiental, para trabajar con los estudiantes y que éstos puedan canalizar las emociones hacia acciones favorables al medio ambiente.

Los resultados obtenidos proporcionan elementos para comprender la importancia de la educación ambiental en la formación de los estudiantes universitarios; en el reconocimiento de que el cambio climático, es en la actualidad, la principal amenaza para la humanidad, así como develar el significado de los factores que originan el cambio climático y los efectos que tienen en el medio ambiente. 
La educación ambiental que se desarrolla en las aulas de muchas instituciones de educación superior y puede contribuir al desarrollo de prácticas profesionales orientadas a atender los impactos del cambio climático.

Las emociones inmersas en las representaciones sociales por lo general se pasan por alto en la investigación, no son objeto de estudio; sin embargo, las emociones se encuentran presentes y constituyen un componente que le imprime un sentido al objeto de representación.

\section{Agradecimientos}

El presente artículo es producto de una investigación aprobada en el Área académica: Diversidad e Interculturalidad de la Universidad Pedagógica Nacional, México.

\section{REFERENCIAS}

BARDÍN, L. Análisis de Contenido. Madrid: Akal, 1986.

BELLO, L. O.; MEIRA, P. Á.; GONZÁLEZ-GAUDIANO, É. J. Representaciones sobre el cambio climático en dos grupos de estudiantes de educación secundaria de España y Bachillerato de México. Revista Mexicana de Investigación Educativa, v. 22, n. 73, p. 505-522, 2017.

BERGER, P.; LUCKMANN, T. La construcción social de la realidad. Buenos Aires: Amorrortu, 2005.

CALIXTO, R. El cambio climático en el pensamiento social de los estudiantes de educación secundaria. In: CALIXTO, R. (coordinador). Investigaciones educativas en torno al cambio climático. México: UPN, 2017. p. 21-50.

DURÁN, M.; ALZATE, M.; LÓPEZ, W.; SABUCEDO, J. M. Emociones y comportamiento pro-ambiental. Revista Latinoamericana de Psicología, v. 39, n. 2, p. 287-296, 2007.

DURKHEIM, E. La división del trabajo social. México: Colofón. (Edición en francés en 1926), 1998.

GONZÁLEZ-GAUDIANO E.; MALDONADOA. L. Representaciones sociales y cambio climático, el caso de Veracruz. In: Ortiz, B. y Velasco, C. (coords.). La percepción social 
del cambio climático. México: Universidad Iberoamericana Puebla y Secretaria de Medio Ambiente y Recursos Naturales, 2012. p. 82-106.

GROB, A. A structural model of environmental attitudes and behaviour. Journal of Environmental Psychology, v. 15, p. 209-220, 1995.

GUTIÉRREZ, S. Emociones y representaciones sociales. Reflexiones teóricas. In: Flores, F. (coordinadora). Representaciones sociales y contextos de investigación con perspectiva género. México: CRIM, 2013. p. 17-44.

GUTIÉRREZ, S.; ARBESÚ M. I.; PIÑA, J. M. Emociones y representaciones sociales. El caso de los estímulos académicos. In: Mireles, O. (coordinadora). Representaciones sociales: emociones, significados y prácticas en la educación superior. México: UNAM, 2012. p. 21-52.

IPCC. Cambio climático 2013: Bases físicas. Resumen para responsables de políticas. Grupo de trabajo I del $5^{\circ}$ Reporte de evaluación del panel intergubernamental de cambio climático. Génova: IPCC, 2013.

IPCC. Cambio climático 2014: Impactos, adaptación y vulnerabilidad, Suiza: Grupo Intergubernamental de Expertos sobre el Cambio Climático, 2014. Disponible: <http:// www.ipcc.ch/pdf/assessment-report/ar5/wg2/ar5_wgII_spm_es.pdf $>$. Acceso en: 15 sept. 2016.

JASPAL, R.; NERLICH, B.; CINNIRELLA M. Human Responses to Climate Change: Social Representation, Identity and Socio-psychological Action. In: Environmental Communication, v. 8, n. 1, p. 110-130, 2014.

KOLLMUS, A.; AGYEMAN, J. Mind the gap: why do people act environmentally and what are the barriers to pro-environmental behaviour? Environmental Education Research, 8, p. 239-260, 2002.

KRIPPENDORFF, K. Metodología del análisis de contenido. Teoría y Práctica. Barcelona: Paidós Ibérica, 1990.

MEIRA, P. Comunicar el Cambio Climático. Escenario social y líneas de acción. Madrid: Ministerio de Medio Ambiente y Medio Rural y Marino. Organismo de Parques Naturales, 2009.

MEIRA, P. A. Ideas de la gente sobre el cambio climático: una relectura. In: Raúl Calixto (coordinador). En la búsqueda de los sentidos y significados de la educación ambiental. México: UPN, 2012. p. 73-91.

MEIRA, P. A.; ARTO, M. Representaciones del cambio climático en estudiantes universitarios en España: aportes para la educación y la comunicación. Educar em Revista, Curitiba, Brasil, Edição Especial, n. 3, p. 15-33, 2013.

MOSCOVICI, S. El psicoánalisis, su imagen y su público. Buenos Aires: Huemel. (Edición en francés, 1961), 1979. 
MOSCOVICI, S. Notes towards a description of social representations. European Journal of Social Psychology, 18 (3), p. 211-250, 1988.

NACIONES UNIDAS. Río + 20. Conferencia de las Naciones Unidas sobre el desarrollo sostenible. El futuro que queremos. Río de Janeiro, Naciones Unidas, 2012. Disponible: $<$ https://rio20.un.org/sites/rio20.un.org/files/a-conf.216-1-1_spanish.pdf.pdf $>$. Acceso en: 19 feb. 2016.

PIÑA, J.M. La teoría de las representaciones sociales. Nociones y linderos. In: Piña, J. M. (coordinador). La subjetividad de los actores de la educación. México: CESUUNAM, 2004. p. 15-54.

TERRÓN, E. Educación ambiental y cambio climático. Representaciones sociales de los universitarios. In: CALIXTO, R. (coordinador). Investigaciones educativas en torno al cambio climático. México: UPN, 2017. p. 77-96.

UNESCO. Conferencia Intergubernamental sobre Educación Ambiental, Tiblisi (URSS). París: UNESCO, 1978.

UNESCO. La Declaración de Ahmedabad: Una llamada a la Acción. Paris: UNESCO, 2007.

WAGNER, W.; HAYES, N.; FLORES, F. (Ed.). El discurso de lo cotidiano y el sentido común: la teoría de las representaciones sociales. México-Barcelona: UNAM-Anthrophos, 2011.

Texto recibido el 05 de octubre de 2017. Texto aprobado el 03 de diciembre de 2017. 
